\title{
A $\beta$ peptide secretion is reduced by Radix Polygalae-induced autophagy via activation of the AMPK/mTOR pathway
}

\author{
HUAN ZHAO ${ }^{1,2}$, ZHI-CHENG WANG ${ }^{3}$, KUI-FENG WANG ${ }^{4}$ and XIAO-YU CHEN ${ }^{1}$ \\ ${ }^{1}$ Department of Histology and Embryology, Anhui Medical University, Hefei, Anhui 230032; \\ ${ }^{2}$ Department of Pathology, The Central Hospital of Lishui, Lishui, Zhejiang $323000 ;{ }^{3}$ Department of Laboratorial Medicine, \\ Huashan Hospital, Shanghai Medical College, Fudan University, Shanghai 200071; ${ }^{4}$ Shanghai Genhouse Technology Co., Ltd., \\ Shanghai 201203, P.R. China
}

Received August 18, 2014; Accepted April 16, 2015

DOI: $10.3892 / \mathrm{mmr} .2015 .3781$

\begin{abstract}
Radix Polygalae is a traditional Chinese medicine that has been used as a sedative and to improve memory for a number of years. The impact of Radix Polygalae in patients with Alzheimer's disease has been investigated. However the mechanisms underlying its effects remain unclear. In the current study, the toxicity of various doses $(100,40,20$, 10,5 and $0 \mu \mathrm{g} / \mathrm{ml}$ ) of Radix Polygalae was measured in the human neuroblastoma cell line (SH-SY5Y) using an MTT assay. Changes in amyloid $\beta(\mathrm{A} \beta)$ levels in the supernatant of Chinese hamster ovary $(\mathrm{CHO})$ cells overexpressing $\beta$-amyloid pro-protein (APP) and BACE1 (CHO-APP/BACE1), were detected using an ELISA assay. In order to confirm that the $\mathrm{A} \beta$ reduction was associated with autophagy, the autophagy marker protein, light chain 3 (LC3), was measured by western blot analysis and autophagosomes were assessed using MDC staining. In addition, the mechanism underlying the autophagy induced by Radix Polygalae was analyzed using western blotting to measure the protein expression of mammalian target of rapamycin (mTOR), p70s6k, Raptor, protein kinase B and adenosine monophosphate-activated protein kinase (AMPK), in addition to the phosphorylated forms of these proteins. The results demonstrated no significant toxicity of Radix Polygalae in SH-SY5Y cells, at a dose of $100 \mu \mathrm{g} / \mathrm{ml}$. The secretion of $\mathrm{A} \beta$ was markedly reduced following treatment with Radix Polygalae, and this reduction occurred in a dose-dependent manner. The autophagy levels were shown to be enhanced in the drug treatment group, using fluorescence microscopy. In addition, levels of LC3II/LC3I, the marker protein of autophagy, were also increased. The results of the current study suggest that Radix Polygalae may aid in the
\end{abstract}

Correspondence to: Dr Xiao-Yu Chen, Department of Histology and Embryology, Anhui Medical University, 81 Meishan Road, Hefei, Anhui 230032, P.R. China

E-mail: cxyayd@163.com

Key words: Radix Polygalae, Alzheimer's disease, autophagy, light chain 3 elimination of the $A \beta$ peptide, via the induction of autophagy, by the AMPK/mTOR signaling pathway. These results may provide a basis for further kin vivo investigation.

\section{Introduction}

Alzheimer's disease (AD) is a neurodegenerative disorder, which ia associated with age and is characterized by progressive memory loss and cognitive dysfunction. Epidemiological studies have shown that the incidence of AD double increases every 5-10 years after the age of 65, indicating that globally the total number of patients with AD will rise to 973 million by 2030 (1). Clinically, AD is characterized by progressive impairments in behavior, cognition and memory (2). The presence of extracellular amyloid plaques, which develop as a result of the deposition of progressively increasing amyloid $\beta$ (A $\beta$ ) peptide levels in the brain, are a key marker of AD (3). The $A \beta$ peptides are important in the pathogenesis of AD. Therefore, inhibiting the generation of $A \beta$ and increasing the rate of clearance of this protein, may be potential therapeutic strategies with which to delay the development of AD (4). While the $A \beta$ hypothesis states that the $\beta$-amyloid protein is involved in the progression of AD pathology, the etiology remains unclear. $A \beta$ is a 39-43 residue amyloidogenic peptide, which is derived from $\beta$-amyloid pro-protein (APP). APP may be cleaved by $\beta$-secretase and $\gamma$-secretase sequentially $(5,6)$, and the resulting hydrolysate is $\sim 4 \mathrm{KDa}$ of $\mathrm{A} \beta$ peptide (5). With increasing age, the efficiency of organisms to eliminate $A \beta$ is reduced, and the concentration of $A \beta$ in the brain is increased, resulting in the formation of plaques. In addition, a previous study indicated that the soluble $\mathrm{A} \beta$ peptide causes severe toxicity to nerve cells, including tau hyperphosphorylation, axonal transport disorder and the disruption of organelle trafficking (7). Therefore, reducing the generation of $A \beta$ (8) or increasing its clearance (9) may be beneficial in the treatment of AD.

Autophagy (macroautophagy in the current study) is the primary approach by which cells remove abnormal proteins and damaged organelles. When autophagy is activated, the substrates requiring removal are surrounded by double-membrane structures, termed autophagosomes $(10,11)$. Autophagosomes fuse with lysosomes to form autolysosomes 
for substrate degradation. Deregulation of autophagy in AD has become an increasing focus of research (12). The enhancement of autophagy may slow the ageing process and reduce age-associated diseases, such as AD (13). For example, a previous study indicated that plaques were reduced, and cognitive deficits significantly improved, at an early age in $3 \times T g-A D$ mice following the administration of rapamycin, which induced autophagy (14).

Mammalian target of rapamycin (mTOR), a $289 \mathrm{KDa}$ serine/threonine protein kinase, is the principle negative regulatory kinase of autophagy, and is also involved in cell growth, proliferation, metabolism and survival $(15,16)$. In addition, mTOR may inhibit autophagy by regulating its downstream target, p70s6 kinase (17). Adenosine monophosphate-activated protein kinase (AMPK) and phosphoinositide 3-kinase $(\mathrm{PI} 3 \mathrm{~K}) /$ protein kinase $\mathrm{B}(\mathrm{Akt})$ are the two upstream regulators of mTOR, each of which are associated with autophagy $(18,19)$. The metabolic sensor, AMPK, has been reported to inhibit mTOR via an effect on its downstream target, Raptor (9). Akt is the positive regulatory kinase of mTOR.

Radix Polygalae is the root of Polygala tenuifolia Willd. and its extract appears to be capable of improving memory (20). In addition, Polygala tenuifolia has been reported to improve cognitive impairment in rat AD models (21). Radix Polygalae extract was used to protect rat neuronal cells in vitro, which were induced by N-methyl-D-aspartate (22). In addition, Tenuifolin, extracted from tenuigenin, has been reported to inhibit A $\beta$ secretion in COS-7 cells expressing APP (23). In the present study, the molecular mechanism underlying the induction of autophagy by Radix Polygalae extract was investigated, as this process was hypothesized to be associated with reductions in $\mathrm{A} \beta$ secretion.

\section{Materials and methods}

Reagents and antibodies. 3-(4,5-Dimethylthiazol-2-yl)2,5-diphenyl-tetrazolium bromide (MTT), dansylcadaverine (MDC) and the rabbit monoclonal anti-light chain 3 (LC3) B antibody (1:1,000; cat. no. L7543) were purchased from Sigma-Aldrich (Shanghai, China). The rabbit monoclonal anti-mTOR (1:1,000; cat. no. 2983), anti-phospho-mTOR (Ser2448; 1:1,000; cat. no. 2971), anti-p70s6k (1:1,000; cat. no. 2708), anti-phospho-p70s6k (Thr389; 1:1,000; cat. no. 9205), anti-AMPK (1:1,000; cat. no. 2532), anti-phospho-AMPK (Thr172; 1:1,000; cat. no. 2535), anti-Raptor (1:500; cat. no. 2280), anti-phospho-Raptor (Ser792 (1:500; cat. no. 2083), anti-Akt (1:1,000; cat. no. 4685) and anti-phospho-Akt (Ser473; 1:1,000; cat. no. 4058) antibodies were obtained from Cell Signaling Technology, Inc. (Shanghai, China). The sheep anti-rabbit IgG antibody conjugated with horseradish peroxidase (IgG-HRP), SDS-PAGE, phenylmethanesulfonyl fluoride, loading buffer, chemiluminescence kit, and penicillin and streptomycin were purchased from Beyotime Institute of Biotechnology (Haimen, China). Fetal bovine serum (FBS), G418 sulfate, DMEM/F12 and F12 basic culture medium were purchased from Life Technologies (Shanghai, China). Paraformaldehyde, Tris-buffered saline (TBS) and TBS supplemented with $0.05 \%$ Tween-20 (TBST), were obtained from Sinopharm Chemical Reagent Co., Ltd. (Shanghai, China).
Preparation of Radix Polygalae extract. Radix Polygalae (Pudong New District Medicine and Medicinal Materials Co., Ltd., Shanghai, China) was extracted using a spin steaming process with a rotary evaporator (Yarong Biochemical Instrument Plant, Shanghai, China) (24).

Cell culture. The SH-SY5Y human neuroblastoma cell line and Chinese hamster ovary (CHO) cells were obtained from Shanghai Institute of Materia Medica (Shanghai, China). SH-SY5Y cells were cultured in DMEM/F12, supplemented with $10 \% \mathrm{FBS}, 100 \mathrm{IU} / \mathrm{ml}$ penicillin and $100 \mu \mathrm{g} / \mathrm{ml}$ streptomycin. CHO cells, stably transfected with APP and BACE1, were cultured in F12 supplemented with $10 \%$ FBS, $100 \mathrm{IU} / \mathrm{ml}$ penicillin, $100 \mu \mathrm{g} / \mathrm{ml}$ streptomycin and $400 \mu \mathrm{g} / \mathrm{ml}$ G418 sulfate. Cells were maintained in an incubator at $37^{\circ} \mathrm{C}$, with an atmosphere of $95 \%$ air and $5 \% \mathrm{CO}_{2}$.

MTT assay for drug toxicity. SH-SY5Y cells were seeded in 96-well plates and treated with different concentrations (100, $40,20,10,5$ or $0 \mu \mathrm{g} / \mathrm{ml}$ ) of Radix Polygalae. Following incubation for $24 \mathrm{~h}, 10 \mu \mathrm{l}$ MTT $(5 \mathrm{mg} / \mathrm{ml})$ was added, and the cells were maintained at $37^{\circ} \mathrm{C}$ for an additional $4 \mathrm{~h}$. The liquid was then discarded, crystals were dissolved in $100 \mu \mathrm{l}$ DMSO and the light absorbance was read at $570 \mathrm{~nm}$ using a Multiskan FC Microplate Reader (Thermo Fisher Scientific, Shanghai, China), with $620 \mathrm{~nm}$ as the reference wavelength. Cells treated with $0 \mu \mathrm{g} / \mathrm{ml}$ Radix Polygalae served as controls (CTL). Radix Polygalae was dissolved in DMSO and while preparing a working solution, isometric DMSO was used in accordance with the drug treatment group.

Measurement of A $\beta 1-40$ secretion in the supernatant. CHO-APP/BACE1 cells were seeded into 24-well plates at a density of 80,000 cells/well. Following treatment with (100, 40, 20, 10, 5 or $0 \mu \mathrm{g} / \mathrm{ml}$ ) Radix Polygalae for $24 \mathrm{~h}$, the A $\beta 1-40$ ELISA kit (Shanghai ExCell Biology, Inc., Shanghai, China) and the Bicinchoninic Acid Protein Assay Reagent (Thermo Fisher Scientific) were used to measure the A $\beta 1-40$ concentration in the supernatant and the total protein respectively. The experiments were conducted in accordance with the manufacturer's instructions. The ratio of A $\beta 1-40$ level and total protein in the DMSO group was similar to the control.

MDC-labeled autophagosomes detected in SH-SY5Y cells. $\mathrm{SH}-\mathrm{SY} 5 \mathrm{H}$ cells were treated with 3 different doses $(0,10$ and $100 \mu \mathrm{g} / \mathrm{ml}$ ) of Radix Polygalae with in the 6-well plate for $24 \mathrm{~h}$, followed by incubation with $50 \mu \mathrm{mol} / 1 \mathrm{MDC}$ at $37^{\circ} \mathrm{C}$ for $30 \mathrm{~min}$. Following incubation, the cells were washed with phosphate-buffered saline and fixed with $4 \%$ paraformaldehyde. Autophagosomes were observed by fluorescence photometry (Olympus, Tokyo, Japan) at the excitation wavelength of $380 \mathrm{~nm}$ and emission filter of $525 \mathrm{~nm}$ (25).

Western blot analysis. SH-SH5Y cells were treated with different doses of Radix Polygalae (100, 40, 20, 10, 5 and $0 \mu \mathrm{g} / \mathrm{ml}$ ) for $24 \mathrm{~h}$ in a 6 -well plate. The total proteins were collected by the addition of radioimmunoprecipitation assay buffer containing $1 \mathrm{mM}$ phenylmethanesulfonyl fluoride, mixed with loading buffer and boiled at $95^{\circ} \mathrm{C}$ for $15 \mathrm{~min}$. Total proteins were separated by SDS-PAGE ( $20 \mu \mathrm{g} /$ lane $)$ and 
transferred to nitrocellulose membranes (Merck Millipore, Boston, MA, USA). The membranes were blocked for $2 \mathrm{~h}$ in TBS (20 mM Tris-HCl, $150 \mathrm{mM} \mathrm{NaCl}, \mathrm{pH} 7.5$ ) containing 5\% non fat milk, then incubated with LC3,(p)-mTOR, (p)-p70s6k, (p)-AMPK, (p)-Raptor and (p)-Akt primary antibodies at $4^{\circ} \mathrm{C}$ overnight. Membranes were washed three times with TBST, and incubated with horseradish peroxidase-linked anti-rabbit IgG for a further $2 \mathrm{~h}$, followed by washing with TBST again. Blots were detected by enhanced chemiluminescence (ECL) and band intensity was analyzed by Image J software 1.48 (National Institutes of Health, Bethesda, MD, USA).

Statistical analysis. Data are expressed as the mean \pm standard deviation. Data for multiple variable comparisons were analyzed by one-way analysis of variance using GraphPad Prism v5.0 software (GraphPad Software, Inc., La Jolla, CA, USA). P $<0.05$ was considered to indicate a statistically significant difference.

\section{Results}

Radix Polygalae exerts no significant effects on the viability of SH-SY5Y cells. The cell viability of human neuroblastoma cells with and without exposure to Radix Polygalae, was measured using an MTT assay. Following $24 \mathrm{~h}$ treatment, cell viability was not significantly different between the control group and the Radix Polygalae-treated groups $(\mathrm{P}>0.05)$. These results implied that the drug is not cytotoxic at doses $<100 \mu \mathrm{g} / \mathrm{ml}$ (Fig. 1).

A 1-40 peptides level is markedly lower in the supernatant of cells treated with Radix Polygalae. The level of the A $31-40$ peptide in the supernatant of CHO-APP/BACE1 cells was measured using an ELISA assay. The data showed that there was a reduction in the level of $A \beta 1-40$ following treatment with Radix Polygalae, and that this effect occurred in a dose-dependent manner. The A $\beta 1-40$ level in the $5 \mu \mathrm{g} / \mathrm{ml}$ group was reduced compared with DMSO group, although this result was not statistically significant. However, the reduction in A $\beta 1-40$ was significantly different from the control group at doses of $\geq 10 \mu \mathrm{g} / \mathrm{ml}(\mathrm{P}<0.01$; Fig. 2).

Autophagy is induced by Radix Polygalae. In order to demonstrate that the $\mathrm{A} \beta$ peptide is degraded by autophagy, autophagy vesicles were detected using the MDC method, and he autophagy protein marker, LC3, was measured by western blotting analysis. Intracellular autophagy vesicles were labeled by MDC, and were observed as green dots. Few vesicles were observed in the control group (Fig. 3A), while an increase in the number of labeled vesicles occurred in the $10 \mu \mathrm{g} / \mathrm{ml}$ group (Fig. 3B) and a marked increase was observed in the $100 \mu \mathrm{g} / \mathrm{ml}$ group (Fig. 3C). LC3I and LC3II are the two forms of the microtubule-associated protein light chain 3 (LC3). When autophagy occurs, LC3I, located in the cytoplasm, is modified and processed by the ubiquitin-proteasome system and converted into LC3II $(9,26)$. Western blot analysis indicated that LC3II/LC3I gradually increased, in accordance with the concentration of Radix Polygalae (Fig. 4).

RadixPolygalaeinducesautophagybyactivatingAMPK/mTOR signaling. In order to investigate the molecular mechanisms

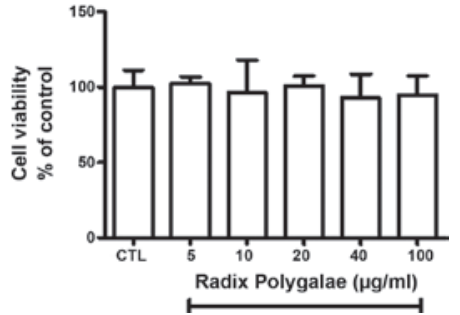

Figure 1. Effects on cell viability in SH-SY5Y cells treated with different concentration of Radix Polygalae for $24 \mathrm{~h}$. Results were obtained from three independent experiments.

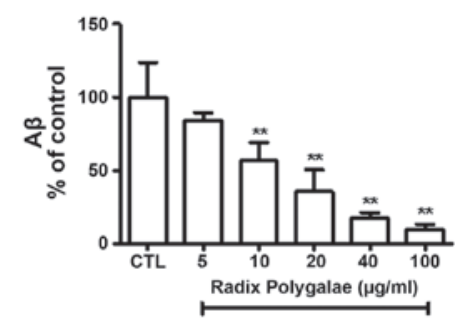

Figure 2. Secretion of A $\beta 1-40$ with different concentrations of Radix Polygalae detected by an ELISA assay. ${ }^{* *} \mathrm{P}<0.01$ vs. the control group. $\mathrm{A} \beta$, amyloid $\beta$.
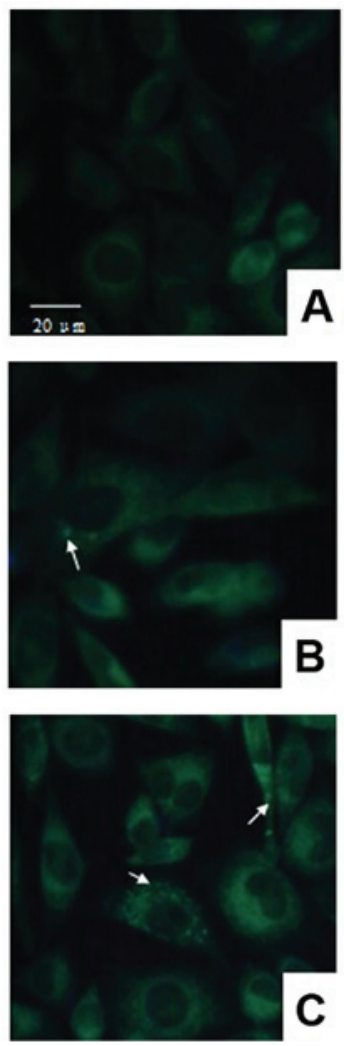

Figure 3. Autophagy vesicles labeled with dansylcadaverine (white arrows) in different groups, observed by fluorescence microscopy. Scale bar, $20 \mu \mathrm{m}$. (A) $0 \mu \mathrm{g} / \mathrm{ml}$; (B) $10 \mu \mathrm{g} / \mathrm{ml}$; (C) $100 \mu \mathrm{g} / \mathrm{ml}$ of Radix Polygalae.

underlying the autophagy induced by Radix Polygalae in neurones, the negative regulator of autophagy, mTOR, in addition to its associated kinases, was examined by western blot analysis. The phosphorylation level of mTOR was reduced in a 

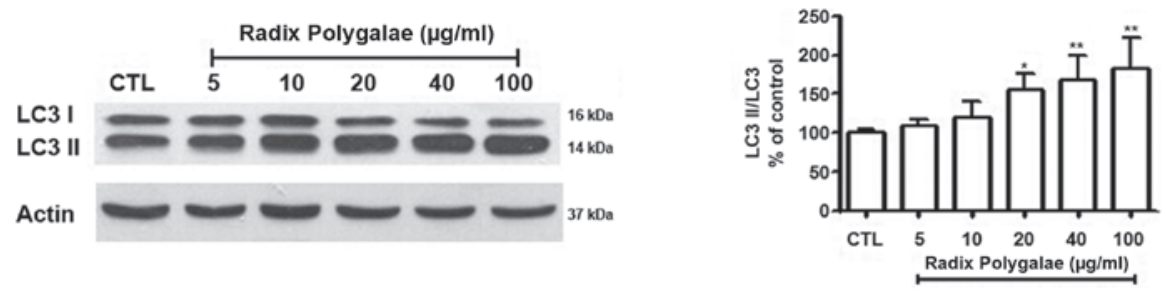

Figure 4. Western blot analysis of the expression of LC3I and LC3II following treatment with Radix Polygalae for $24 \mathrm{~h}$. The autophagy marker protein was measured by western blot analysis. Band intensity was quantified using Image J software. ${ }^{*} \mathrm{P}<0.05$ and ${ }^{* *} \mathrm{P}<0.01$ vs. the control group. LC3, light chain 3 .
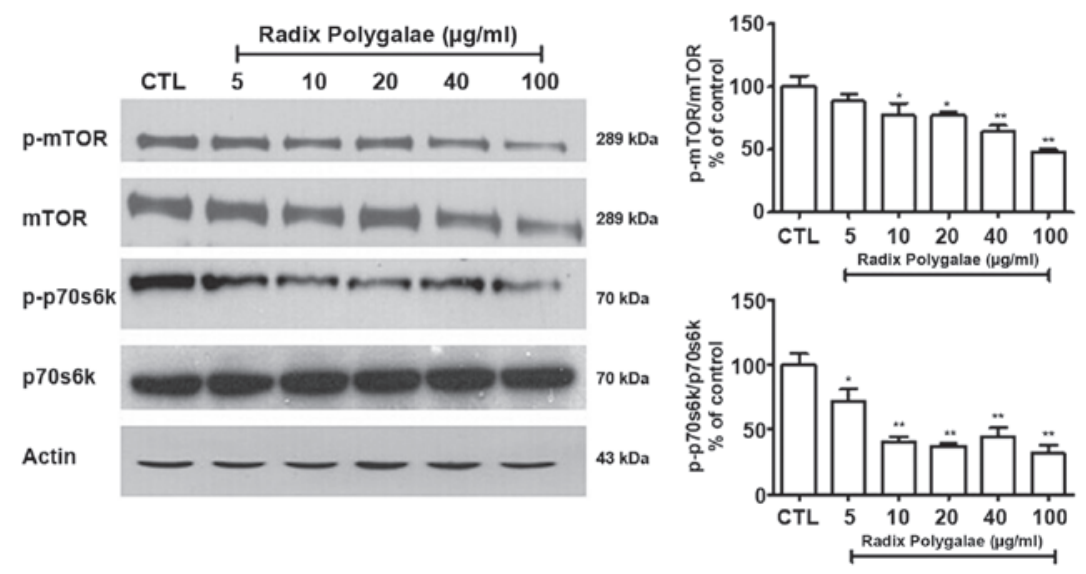

Figure 5. Effect of Radix Polygalae on the phosphorylation level of mTOR at Ser2448, and of p70s6k at Thr389, in SH-SY5Y cells. ${ }^{*} \mathrm{P}<0.05$ and ${ }^{* *} \mathrm{P}<0.01$ vs. the control group. mTOR, mammalian target of rapamycin; p-, phosphorylated.
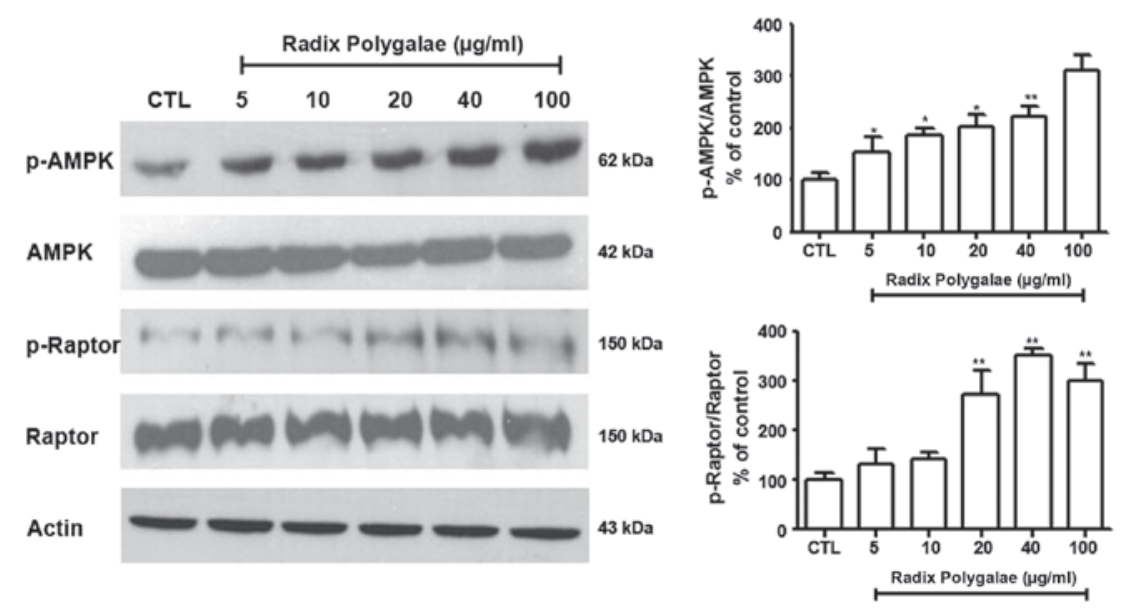

Figure 6. Effect of Radix Polygalae on the phosphorylation level of AMPK at Thr172, and of Raptor at Ser792, in SH-SY5Y cells. ${ }^{*} \mathrm{P}<0.05$ and ${ }^{* * *} \mathrm{P}<0.01$ vs. the control group. AMPK, adenosine monophosphate-activated protein kinase; p-, phosphorylated.
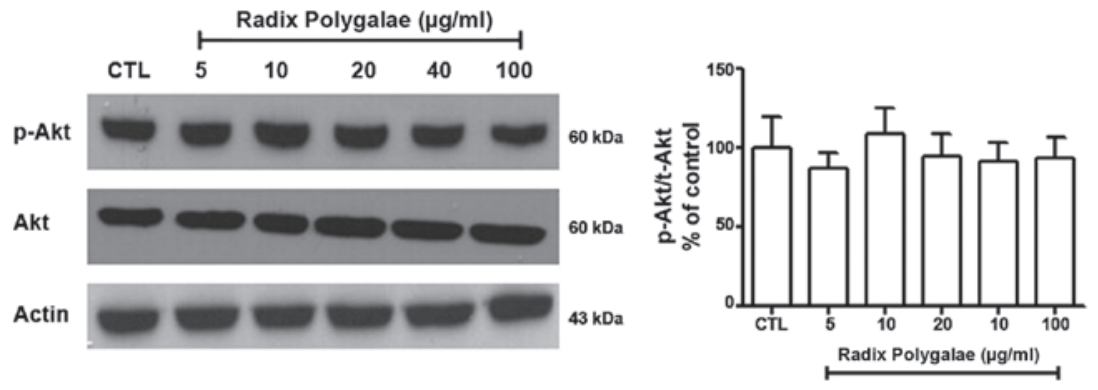

Figure 7. Effect of Radix Polygalae on the phosphorylation level of Akt at Ser473 in SH-SY5Y cells. "P<0.05 and ${ }^{* *} \mathrm{P}<0.01$ vs. the control group. Akt, protein kinase B; p-, phosphorylated. 
dose-dependent manner in the Radix Polygalae-treated groups. This indicates that Radix Polygalae may increase the level of autophagy. In addition, the downstream signaling kinase of mTOR, p70s6k, which also participates in the regulation of autophagy, was also inhibited by Radix Polygalae (Fig. 5).

In order to investigate the upstream pathway of mTOR, which may be affected by Radix Polygalae, the expression of AMPK and its downstream target, Raptor, was measured (27). With increasing doses of Radix Polygalae, the phosphorylation level of AMPK at Thr172 was increased, as was the phosphorylation of Raptor at Ser792 (Fig. 6).

Akt is another kinase that is known to activate mTOR (15). The results of the present study demonstrated that the phosphorylation level of Akt at Ser473 in the different groups was not significantly altered (Fig. 7).

\section{Discussion}

$\mathrm{A} \beta$ is an important protein in the pathogenesis of $\mathrm{AD}$, and has become an increasing focus of the research into the development of novel anti-AD treatments (28-31). Reducing the levels of $\mathrm{A} \beta$ in the brain, with the aim of improving cognitive function and quality of life for patients with AD, are currently key aims in AD research. However, a specific and effective drug with which to treat AD remains to be developed, although the understanding of AD has advanced rapidly $(20,32)$. In previous years, traditional Chinese medicine (TCM) products have gained attention for their potential use in AD treatment, due to the low toxicity and the fact that they are easy to obtain (20). Radix Polygalae, a TCM that is used to improve memory, has been previously studied, however the mechanisms involved remain to be elucidated (21-23). In the current study, the effect of Radix Polygalae on A $\beta$ peptide levels was investigated in vitro.

Serious damage to neurons by $\mathrm{A} \beta$ peptides results in the formation of amyloid plaques and also leads to induction of the inflammatory response (33) and hyperphosphorylation of Tau $(34,35)$, resulting in neuronal death. In the present study, secreted A $\beta$ was detected in the CHO-APP/BACE1 supernatant, and the levels were significantly reduced following treatment with Radix Polygalae, suggesting that this compound simulates the removal of the $A \beta$ peptide. Autophagy, which is the primary method of removing abnormal proteins and organelles from cells, was hypothesized to have been involved in this process. In order to confirm this hypothesis, MDC staining was used to detect autophagosomes. In addition, levels of the autophagy marker protein, LC3, were measured. The results from these two experiments supported the hypothesis.

In order to investigate the signaling mechanism underlying the induction of autophagy by Radix Polygalae, the mTOR pathway was assessed, due to its association with autophagy. In a previous study, mTOR was shown to be inhibited by rapamycin, while autophagy was increased, with the result that $\beta$ amyloid plaque in a mouse model of AD decreased and cognitive function improved (14,36). p70s6k is the downstream target of mTOR. It is regulated by mTOR and participates in the inhibition of autophagy (17,37). In the current study, it was observed that the levels of mTOR and p70s6k were reduced by the addition of Radix Polygalae, indicating that autophagy had been induced. AMPK and PI3K/Akt are the two upstream regulators of mTOR, and AMPK is the key energy-sensing kinase that regulates cellular energy homeostasis in eukaryotes (27). AMPK regulates mTOR by phosphorylating Raptor at Ser792 $(9,38)$. The Akt pathway is an additional upstream regulator of mTOR, exerting its action by phosphorylating Akt at Ser473 (16). In the current study, the phosphorylation of AMPK/Raptor increased. By contrast, Akt was not observed to be activated. These results support the hypothesis that Radix Polygalae induces autophagy via the activation AMPK/Raptor/mTOR signaling.

In conclusion, autophagy is involved in the removal of $A \beta$ peptide by Radix Polygalae. The basic signaling mechanism underlying this effect was detected, and the results of the current study may provide a basis for further investigation into the use of this compound in the treatment of AD.

\section{Acknowledgements}

This study was supported by grants from the National Natural Science Foundation of China (grant nos. 81373421 and 81270650).

\section{References}

1. Feng Y and Wang X: Antioxidant therapies for Alzheimer's disease. Oxid Med Cell Longev 2012: 472932, 2012.

2. Huang Y and Mucke L: Alzheimer mechanisms and therapeutic strategies. Cell 148: 1204-1222, 2012.

3. Bondareff W: Age-related changes in brain extracellular space affect processing of amyloid- $\beta$ peptides in Alzheimer's disease. J Alzheimers Dis 35: 1-6, 2013.

4. Shi TY, Zhao DQ, Wang HB, et al: A new chiral pyrrolyl $\alpha$-nitronyl nitroxide radical attenuates $\beta$-amyloid deposition and rescues memory deficits in a mouse model of Alzheimer disease. Neurotherapeutics 10: 340-353, 2013.

5. Cappai R and White AR: Amyloid $\beta$. Int J Biochem Cell Biol 31: 885-889, 1999.

6. Cavallucci V, D'Amelio $\mathrm{M}$ and Cecconi $\mathrm{F}$ : $\mathrm{A} \beta$ toxicity in Alzheimer's disease. Mol Neurobiol 45: 366-378, 2012.

7. Sanchez-Varo R, Trujillo-Estrada L, Sanchez-Mejias E, et al: Abnormal accumulation of autophagic vesicles correlates with axonal and synaptic pathology in young Alzheimer's mice hippocampus. Acta Neuropathol 123: 53-70, 2012.

8. Zhu Z, Li C, Wang X, Yang Z, Chen J, Hu L, Jiang H and Shen X: 2,2',4'-trihydroxychalcone from Glycyrrhiza glabra as a new specific BACE1 inhibitor efficiently ameliorates memory impairment in mice. J Neurochem 114: 374-385, 2010.

9. Arsikin K, Kravic-Stevovic T, Jovanovic M, Ristic B, Tovilovic G, Zogovic N, Bumbasirevic V, Trajkovic V and Harhaji-Trajkovic L: Autophagy-dependent and -independent involvement of AMP-activated protein kinase in 6-hydroxydopamine toxicity to SH-SY5Y neuroblastoma cells. Biochim Biophys Acta 1822: 1826-1836, 2012.

10. Tung YT, Wang BJ, Hu MK, Hsu WM, Lee H, Huang WP and Liao YF: Autophagy: a double-edged sword in Alzheimer's disease. J Biosci 37: 157-165, 2012.

11. Periyasamy-Thandavan S, Jiang M, Schoenlein P and Dong Z: Autophagy: Molecular machinery, regulation and implications for renal pathophysiology. Am J Physiol Renal Physiol 297: F244-F256, 2009.

12. Cheung ZH and Ip NY: Autophagy deregulation in neurodegenerative diseases-recent advances and future perspectives. J Neurochem 118: 317-325, 2011.

13. Kaushik S and Cuervo AM: Autophagy as a cell-repair mechanism: Activation of chaperone-mediated autophagy during oxidative stress. Mol Aspects Med 27: 444-454, 2006.

14. Majumder S, Richardson A, Strong R and Oddo S: Inducing autophagy by rapamycin before, but not after, the formation of plaques and tangles ameliorates cognitive deficits. PLoS One 6: e25416, 2011 
15. Chong ZZ, Shang YC, Zhang L, Wang S and Maiese K: Mammalian target of rapamycin: Hitting the bull's-eye for neurological disorders. Oxid Med Cell Longev 3: 374-391, 2010.

16. Wu X, Kihara T, Akaike A, Niidome T and Sugimoto $\mathrm{H}$ : $\mathrm{PI} 3 \mathrm{~K} / \mathrm{Akt} / \mathrm{mTOR}$ signaling regulates glutamate transporter 1 in astrocytes. Biochem Biophys Res Commun 393: 514-518, 2010.

17. Klionsky DJ, Meijer AJ, Codogno P, Neufeld TP and Scott RC: Autophagy and p70S6 kinase. Autophagy 1: 59-61, 2005.

18. Din FV, Valanciute A, Houde VP, Zibrova D, Green KA Sakamoto K, Alessi DR and Dunlop MG: Aspirin inhibits mTOR signaling, activates AMP-activated protein kinase, and induces autophagy in colorectal cancer cells. Gastroenterology 142: 1504-15.e3, 2012

19. Saiki S, Sasazawa Y,Imamichi Y, et al: Caffeine induces apoptosis by enhancement of autophagy via PI3K/Akt/mTOR/p70S6K inhibition. Autophagy 7: 176-187, 2011.

20. Lin Z, Gu J, Xiu J, Mi T, Dong J and Tiwari JK: Traditional chinese medicine for senile dementia. Evid Based Complement Alternat Med 2012: 692621, 2012.

21. Lee HJ, Ban JY, Koh SB, Seong NS, Song KS, Bae KW and Seong YH: Polygalae radix extract protects cultured rat granule cells against damage induced by NMDA. Am J Chin Med 32: 599-610, 2004

22. Park CH, Choi SH, Koo JW, Seo JH, Kim HS, Jeong SJ and Suh YH: Novel cognitive improving and neuroprotective activities of Polygala tenuifolia Willdenow extract, BT-11. J Neurosci Res 70: 484-492, 2002.

23. Lv J, Jia H, Jiang Y, Ruan Y, Liu Z, Yue W, Beyreuther K, Tu P and Zhang D: Tenuifolin, an extract derived from tenuigenin, inhibits amyloid- $\beta$ secretion in vitro. Acta Physiol (Oxf) 196: 419-425, 2009

24. Melo MC, Gadelha DN, Oliveira TK and Brandt CT: Alcohol extract of Schinu sterebinthifolius raddi (anacardiaceae) as a local antimicrobial agent in severe autogenously fecal peritonitis in rats. Acta Cir Bras 29 (Suppl 1): 52-56, 2014.

25. Munafó DB and Colombo MI: A novel assay to study autophagy: Regulation of autophagosome vacuole size by amino acid deprivation. J Cell Sci 114: 3619-36291, 2001.

26. Hung SY, Huang WP, Liou HC and Fu WM: Autophagy protects neuron from Abeta-induced cytotoxicity. Autophagy 5: 502-510, 2009.

27. CaiZ, Yan LJ,LiK,Quazi SH and Zhao B: Roles of AMP-activated protein kinase in Alzheimer's disease. Neuromolecular Med 14: $1-14,2012$.
28. Arbel M and Solomon B: Immunotherapy for Alzheimer's disease: Attacking amyloid beta from the inside. Trends Immunol 28: 511-513, 2007.

29. Jeon S, Bose S, Hur J, Jun K, Kim YK, Cho KS and Koo BS: A modified formulation of Chinese traditional medicine improves memory impairment and reduces $A \beta$ level in the Tg-APPswe/PS1dE9 mouse model of Alzheimer's disease. J Ethnopharmacol 137: 783-789, 2011.

30. Lai AY and McLaurin J: Inhibition of amyloid-beta peptide aggregation rescues the autophagic deficits in the TgCRND8 mouse model of Alzheimer disease. Biochim Biophys Acta 1822: 1629-1637, 2012.

31. Eisenberg D and Jucker M: The amyloid state of proteins in human diseases. Cell 148: 1188-1203, 2012.

32. Gao J, Inagaki Y, Li X, Kokudo N and Tang W: Research progress on natural products from traditional Chinese medicine in treatment of Alzheimer's disease. Drug Discov Ther 7: 46-57, 2013.

33. Meraz-Ríos MA, Toral-Rios D, Franco-Bocanegra D, Villeda-Hernández $\mathrm{J}$ and Campos-Peña V: Inflammatory process in Alzheimer's Disease. Front Integr Neurosci 7: 59, 2013.

34. Cuchillo-Ibáñez I, Balmaceda V, Botella-López A, Rabano A Avila J and Sáez-Valero J: Beta-amyloid impairs reelin signaling. PLoS One 8: e72297, 2013.

35. Tokutake T, Kasuga K, Yajima R, Sekine Y, Tezuka T, Nishizawa $M$ and Ikeuchi T: Hyperphosphorylation of Tau induced by naturally secreted amyloid- $\beta$ at nanomolar concentrations is modulated by insulin-dependent Akt-GSK3 $\beta$ signaling pathway. J Biol Chem 287: 35222-35233. 2012

36. Spilman P, Podlutskaya N, Hart MJ, Debnath J, Gorostiza O, Bredesen D, Richardson A, Strong R and Galvan V: Inhibition of mTOR by rapamycin abolishes cognitive deficits and reduces amyloid-beta levels in a mouse model of Alzheimer's disease. PLoS One 5: e9979, 2010.

37. Lafay-Chebassier C, Paccalin M, Page G, Barc-Pain S, Perault-Pochat MC, Gil R, Pradier L and Hugon J: mTOR/p70S6k signalling alteration by $\mathrm{Ab}$ exposure as well as in APP-PS1 transgenic models and in patients with Alzheimer's disease. J Neurochem 94: 215-225, 2005.

38. Lee JW, Park S, Takahashi Y and Wang HG: The association of AMPK with ULK1 regulates autophagy. PLoS One 5: e15394, 2010. 